\title{
EFEITO DAS CIANOBACTÉRIAS Synechococcus leopoliensis E Nostoc sp. SOBRE Colletotrichum sublineolum E NA INTERAÇÃO DO PATÓGENO COM PLANTAS DE SORGO*
}

\author{
ROBSON M. DI PIERO** \& SÉRGIO F. PASCHOLATI*** \\ Laboratório de Fisiologia e Bioquímica Fitopatológica, Departamento de Entomologia, Fitopatologia e Zoologia \\ Agrícola, Escola Superior de Agricultura "Luiz de Queiroz", Cx. Postal 09, CEP 13418-900, Piracicaba/SP, \\ Fax (019) 3434-4839, e-mail: sfpascho@ carpa.ciagri.usp.br
}

(Aceito para publicação em 18/02/2002)

Autor para correspondência: Sérgio Florentino Pascholati

DI PIERO, R.M. \& PASCHOLATI, S.F. Efeito das cianobactérias Synechococcus leopoliensis e Nostoc sp. sobre Colletotrichum sublineolum e na interação do fitopatógeno com plantas de sorgo. Fitopatologia Brasileira 27:163-169. 2002.

\section{RESUMO}

Entre os patógenos que provocam perdas na cultura de sorgo (Sorghum bicolor), Colletotrichum sublineolum, agente causal da antracnose, é tido como um dos principais problemas. Com o objetivo de buscar medidas alternativas para o controle da doença, testou-se o efeito de duas cianobactérias, Synechococcus leopoliensis e Nostoc sp., sobre o fitopatógeno em condições de laboratório e na proteção de plantas de sorgo mantidas em casa de vegetação. $O$ filtrado de cultura de ambas cianobactérias estimulou a germinação de conídios do fungo, em testes conduzidos sobre lâminas cobertas com poliestireno. O crescimento micelial in vitro do patógeno também foi estimulado por S. leopoliensis. As cianobactérias não induziram o acúmulo de fitoalexinas em mesocótilos estiolados de sorgo. A proteção de uma cultivar suscetível, no estágio de seis folhas verdadeiras, só foi alcançada quando os tratamentos com cianobactérias foram aplicados em sorgo por duas vezes antes da inoculação das plantas com o patógeno. $\mathrm{O}$ efeito do estímulo das cianobactérias sobre $C$. sublineolum pode ser atribuído aos nutrientes presentes nos filtrados de cultura cianobacterianos. A ausência de efeito antagonista direto ao fitopatógeno e a incapacidade de desencadear o acúmulo de fitoalexinas, uma importante resposta de defesa em sorgo, por parte das cianobactérias poderiam explicar o baixo nível de controle da antracnose. Com base nas condições experimentais do presente trabalho e nos resultados obtidos, conclui-se que $S$. leopoliensis e Nostoc sp. não revelaram potencial para atuarem como agentes biológicos de controle de C. sublineolum em sorgo.

Palavras-chave adicionais: antracnose do sorgo, controle biológico, fitoalexinas.

\section{ABSTRACT \\ Effect of the cyanobacteria Synechococcus leopoliensis and Nostoc sp. on Colletotrichum sublineolum and on the interaction of the fungus with sorghum plants}

Among the pathogens that cause damage to sorghum (Sorghum bicolor), Colletotrichum sublineolum, the causal agent of anthracnose, is one of the major problems. In trying to find alternative ways to control the disease, the effect of two cyanobacteria, Synechococcus leopoliensis and Nostoc sp., was tested on fungal development in vitro and on the protection of sorghum plants kept under greenhouse conditions. Filtrates from both cyanobacteria improved conidium germination in assays carried out on glass slides covered with polystyrene. The in vitro mycelial growth of the pathogen was stimulated by $S$. leopoliensis too. The cyanobacteria did not induce the accumulation of phytoalexins in etiolated sorghum mesocotyls.
The protection of a susceptible sorghum cultivar, with six true leaves, was low and only observed when the cyanobacterium treatments were applied twice before the inoculation of the plants with the pathogen. The stimulation effect of the cyanobacteria on $C$. sublineolum was likely due to nutrients present in the cyanobacteria culture filtrates. The low level of antracnose control may be explained by the low cyanobacterial capacity to produce fungal inhibitory compounds or to induce an important resistance response in the plants, such as, the phytoalexin accumulation. Therefore, based upon this work, S. leopoliensis and Nostoc sp. did not exhibit potential as biological control agents of C. sublineolum in sorghum.

\section{INTRODUÇÃO}

A antracnose é considerada a principal doença do sorgo [Sorghum bicolor (L.) Moench] no Brasil, pela sua ampla distribuição geográfica e pelos danos que ocasiona à cultura.

\footnotetext{
*Parte da Dissertação de Mestrado do primeiro autor. ESALQ. Piracicaba ** Bolsista da FAPESP

*** Bolsista do CNPq.
}

Casela \& Frederiksen (1993) relataram prejuízos acima de $50 \%$ na produção, quando somente as folhas de cultivares suscetíveis foram afetadas. A doença é problema em regiões mais quentes e úmidas, embora perdas severas possam ocorrer em áreas sujeitas a breves períodos de chuva seguidos de seca prolongada. O agente causal, Colletotrichum sublineolum Henn. (sinonímia C. graminicola Ces. Wils.), caracteriza-se por afetar folhas, colmo, panícula e grãos. 


\section{R.M. Di Piero \& S.F. Pascholati}

A medida mais eficiente para o controle da doença envolve o emprego de cultivares resistentes. Entretanto, a variabilidade existente na população do patógeno dificulta, muitas vezes, a estratégia de adotar a resistência genética como medida isolada para o controle. Além disso, muitos dos genótipos suscetíveis apresentam características agronômicas desejáveis. Esses materiais contêm a informação genética para resistência, porém esta é expressa de forma inadequada, com velocidade e/ou magnitude insuficientes para controlar o agente de infecção (Kuc, 1987). A indução de resistência tem por objetivo justamente ativar os mecanismos latentes de resistência de um hospedeiro suscetível ou moderadamente resistente de modo que o mesmo tenha sucesso na defesa contra o patógeno durante a interação. Essa técnica pode perfeitamente adequar-se em um programa de controle integrado de doenças e contribuir para que genótipos de alto valor agronômico continuem ou passem a ser utilizados no campo.

Para que o processo de indução de resistência seja desencadeado, é necessário que o hospedeiro seja estimulado por agentes bióticos e/ou abióticos. Entre os indutores bióticos, a literatura apresenta vários estudos onde microrganismos mostraram-se efetivos em induzir resistência em plantas. Metabólitos produzidos por microrganismos saprofíticos proporcionaram um alto grau de controle no campo do oídio em pepino (Cucumis sativus L.) e especialmente em trigo [Triticum aestivum (L.) Thell.], onde a doença foi reduzida em mais de 90\% (Schönbeck et al., 1982). Roveratti (1989) demonstrou que a ferrugem do cafeeiro (Coffea arabica L.) podia ser controlada através do uso de Saccharomyces cerevisiae Meyen. A linhagem Pf1 de Pseudomonas fluorescens Migula, utilizada em formulação comercial $(10 \mathrm{~g} /$ $\mathrm{Kg}$ ) no tratamento de sementes de arroz (Oryza sativa L.), controlou eficientemente a bruzone (Vidhyasekaran et al., 1997). Em tomate (Lycopersicon esculentum Mill.), alface (Lactuca sativa L.), pimentão (Capsicum annum L.), feijão (Phaseolus vulgaris L.) e fumo (Nicotiana tabacum L.), a aplicação de Trichoderma harzianum Rifai T39 em sítios espacialmente separados a partir da inoculação com Botrytis cinerea Pers. \& Fr., resultou em uma redução de 25-100\% nos sintomas de mofo cinzento, em função do atraso ou supressão na velocidade de formação das lesões (De Meyer $e t$ al., 1998).

Por sua vez, as cianobactérias são microrganismos procariotos, capazes de realizar fotossíntese. As formas unicelulares reproduzem-se por fissão binária, enquanto as filamentosas sofrem fragmentação, e a multiplicação sob condições controladas é relativamente fácil. Diversos trabalhos relatam a capacidade das cianobactérias em produzirem vários compostos biologicamente ativos, os quais incluem antibióticos com efeito sobre vírus, fungos e bactérias causadores de doenças em seres humanos e animais (Cannel, 1993; Kulik, 1995). Além disso, alguns fitopatógenos como Rhizoctonia solani Kühn e Sclerotinia sclerotiorum (Lib.) de Bary tiveram o crescimento in vitro inibido por produtos celulares da cianobactéria Nostoc muscorum Agardh (De Caire et al., 1987).
Apesar da riqueza em compostos ativos encontrados em cianobactérias, não há estudos envolvendo a utilização desses procariotos na proteção vegetal. Assim, procurou-se estudar o efeito de duas cianobactérias, Synechococcus leopoliensis (Racib) Kom. e Nostoc sp., na interação sorgo C. sublineolum, verificando-se a influência dos metabólitos produzidos por esses microrganismos diretamente sobre o desenvolvimento do fitopatógeno, bem como sobre plantas de sorgo suscetíveis ao fungo, procurando demonstrar algum efeito de proteção das mesmas contra o fitopatógeno.

\section{MATERIAL E MÉTODOS}

\section{Condições de crescimento das cianobactérias $S$. leopoliensis e Nostoc sp. e do fitopatógeno Colletotrichum sublineolum}

Os isolados de S. leopoliensis e Nostoc sp. foram cedidos, respectivamente, pelo Prof. Dr. Carlos A. Labate, do Departamento de Genética - ESALQ/USP, e pela pesquisadora Dra. Marli de Fátima Fiori, do Centro de Energia Nuclear na Agricultura/USP. A cianobactéria S. leopoliensis foi doada ao Prof. Labate pelo Dr. David T. Canvin, Departamento de Biologia, Universidade Queen's, Kingston, Ontario, Canadá, enquanto Nostoc sp. foi isolada a partir de sedimentos de várzea da região Amazônica. As culturas de S. leopoliensis e Nostoc sp. foram cultivadas em meio líquido BG-11 (Allen, 1968) e AA/4 (Allen \& Arnon, 1955), respectivamente, a 30 ${ }^{\circ} \mathrm{C}$ e sob luminosidade constante de $50 \mu$ mol. $\mathrm{m}^{-2} \cdot \mathrm{s}^{-1}$. A taxa de crescimento das cianobactérias, monitorada pela dosagem do conteúdo de clorofila $a$ ao longo do tempo (Aguiar, 1992), definiu o momento adequado para a obtenção das preparações a serem utilizadas nos testes.

Culturas puras de C. sublineolum foram mantidas em BDA, a $25{ }^{\circ} \mathrm{C}$, sob luz constante, visando estimular o crescimento micelial. Para a esporulação, o fungo foi cultivado em meio de aveia, a $23{ }^{\circ} \mathrm{C}$, sob luz negra (faixa de comprimento de onda em torno de $320 \mathrm{~nm}$ ).

\section{Obtenção das preparações das cianobactérias utilizadas nos ensaios}

Dois tipos de preparações foram obtidas para estudo: a) suspensão de células (sc) obtida diretamente a partir do crescimento das células nos respectivos meios de cultivo; b) filtrado (f) obtido após centrifugação da sc a $8.000 \mathrm{~g} / 25 \mathrm{~min}$ a $4^{\circ} \mathrm{C}$, seguida da pré-filtração à vácuo em papel de filtro Whatmann $\mathrm{n}^{\circ} 3$ e filtração em membrana tipo Millipore (diâmetro do poro $=0,2 \mu \mathrm{m}$ ).

\section{Determinação dos conteúdos de açúcares redutores e proteínas totais nos filtrados das cianobactérias}

Os conteúdos de açúcares redutores e proteínas totais presentes nos filtrados das cianobactérias foram determinados pelos métodos de Lever (1972) e de Bradford (1976), respectivamente. Para quantificar os açúcares, $0,5 \mathrm{ml}$ de filtrado reagiu com 1,5 $\mathrm{ml}$ de hidrazida do ácido $p$-hidroxibenzóico a $100{ }^{\circ} \mathrm{C}$ por $5 \mathrm{~min}$, após o que a mistura foi resfriada e a sua 
absorbância a $410 \mathrm{~nm}$ determinada em espectrofotômetro. Para a quantificação de proteínas, foram adicionados $0,2 \mathrm{ml}$ do reagente de Bradford concentrado a cada $0,8 \mathrm{ml}$ de filtrado e, após $5 \mathrm{~min}$, foi realizada a leitura de absorbância a 595 nm. As concentrações de açúcares e proteínas nos filtrados foram determinadas utilizando-se curvas padrões, respectivamente, de glicose e albumina de soro bovino.

\section{Influência das cianobactérias na germinação de conídios} e formação de apressórios por $\boldsymbol{C}$. sublineolum

A influência das preparações das cianobactérias sobre a germinação dos conídios e a formação de apressórios por C. sublineolum foi determinada através do uso de lâminas de vidro para microscopia recobertas com uma camada de poliestireno (Leite \& Nicholson, 1992). Cada lâmina recebeu duas gotas de $50 \mu \mathrm{l}$ de um dos tratamentos (preparações cianobacterianas, meio de cultivo BG 11, meio de cultivo AA/ 4 ou água destilada). A seguir, foram adicionados $50 \mu \mathrm{da}$ suspensão de esporos do fungo ( 1 x $10^{5}$ conídios/ml), em contato com as gotículas dos tratamentos. As lâminas, em número de três para cada tratamento, foram mantidas em câmara úmida, transparente e sob luz fluorescente constante, a $25^{\circ} \mathrm{C}$. A porcentagem de germinação de conídios e formação de apressórios foi avaliada $20 \mathrm{~h}$ após o início do experimento, através do emprego de azul de algodão com lactofenol e observação em microscópio ótico.

Efeito das cianobactérias sobre o crescimento de $C$. sublineolum em meio de cultivo

Os filtrados das cianobactérias, provenientes de culturas com diferentes idades, foram incorporados em BDA a $45^{\circ} \mathrm{C}$, nas proporções de 20 ou $40 \%$ e vertidos em placas de Petri. Após solidificação do meio de cultivo, cada placa recebeu um disco de $0,5 \mathrm{~cm}$ de diâmetro contendo crescimento micelial de $C$. sublineolum, na parte central. As placas, em número de cinco para cada tratamento, foram mantidas a 26 $\pm 1{ }^{\circ} \mathrm{C}$, sob condições de escuro. $\mathrm{O}$ crescimento diametral (em $\mathrm{cm}$ ) das colônias fúngicas foi registrado periodicamente até o momento em que as colônias presentes nas placas-controle atingiram todo o diâmetro das mesmas.

\section{Efeito das cianobactérias no acúmulo de fitoalexinas em mesocótilos de sorgo}

Sementes de sorgo da cultivar Brandes (resistente a C. sublineolum) foram embebidas em água por $6 \mathrm{~h}$, sob aeração e a temperatura ambiente, e incubadas entre camadas de papel de filtro umedecidas, no escuro a $28^{\circ} \mathrm{C}$. Após cinco dias, as plântulas foram expostas a $4 \mathrm{~h}$ de luz para a paralização da elongação dos mesocótilos. Estes foram coletados e colocados no interior de tubos de ensaio (uma repetição = um tubo com cinco mesocótilos) contendo $3 \mathrm{ml}$ dos diferentes preparados das cianobactérias, sendo incubados sob luz fluorescente constante, umidade relativa alta e temperatura de $25{ }^{\circ} \mathrm{C}$ por $60 \mathrm{~h}$. Após esse período, eliminouse $0,5 \mathrm{~cm}$ da base dos mesocótilos, e os $2,0 \mathrm{~cm}$ acima foram pesados e colocados em $1,4 \mathrm{ml}$ de metanol $80 \%$ acidificado
( $\mathrm{HCl} 0,1 \%$ ) a $4{ }^{\circ} \mathrm{C}$ durante cinco dias. Posteriormente, as frações metanólicas das amostras foram separadas dos tecidos e a absorbância determinada em espectrofotômetro a 490 $\mathrm{nm}$ (Nicholson et al., 1987). A atividade elicitora dos preparados foi calculada em termos de Absorbância a 490 $\mathrm{nm} / \mathrm{g}$ tecido fresco. Os tratamentos-controle consistiram da incubação dos mesocótilos em água, e nos meios de cultivo das cianobactérias (BG 11 e AA/4). Utilizou-se uma suspensão de esporos de C. sublineolum (1 x $10^{5}$ conídios/ml) como controle positivo. Foram realizadas cinco repetições para cada tratamento.

\section{Efeito protetor das cianobactérias na interação sorgo x $C$. sublineolum}

Plantas de sorgo da cultivar Tx398-B (suscetível), apresentando seis folhas verdadeiras, foram aspergidas com preparações das cianobactérias (tratamento indutor) ou com água destilada esterilizada ou com os meios líquidos (controles), até o ponto de escorrimento. Os tratamentos foram efetuados em uma folha marcada por planta (quinta folha da base para o ápice). Após os tratamentos, as plantas permaneceram no interior de câmaras de crescimento, com temperatura variando de $25 \pm 2{ }^{\circ} \mathrm{C}$, fotoperíodo de $14 \mathrm{~h}$. Aspergiram-se as suspensões de conídios de $C$. sublineolum (1 X $10^{5}$ conídios/ml) na superfície superior das folhas marcadas, $48 \mathrm{~h}$ após os tratamentos indutores. As plantas, então, foram dispostas em câmara úmida, com fotoperíodo de $14 \mathrm{~h}$ e temperatura de $23 \pm 1{ }^{\circ} \mathrm{C}$, durante as $24 \mathrm{~h}$ subsequentes à inoculação. A seguir, as plantas foram transferidas para casa de vegetação onde permaneceram até o final do experimento. Em outro teste, os tratamentos foram aplicados em esquema booster, com a realização de uma segunda aplicação em sorgo $24 \mathrm{~h}$ após a primeira, e a inoculação com o fitopatógeno $48 \mathrm{~h}$ após a segunda aplicação. Nesse teste, foram incluídos dois tratamentos: suspensão de esporos autoclavada de C. sublineolum $\left(1 \times 10^{5}\right.$ conídios $\left./ \mathrm{ml}\right)$ e o indutor químico de defesa vegetal, éster S-metil do ácido benzo-(1,2,3)-tiadiazole-7-carbotióico (nome comum: acibenzolar S-metil, ASM), na dosagem de 50 ppm de ingrediente ativo. Foram feitas quatro repetições por tratamento em cada teste. Cada repetição consistiu de um vaso com quatro plantas. $\mathrm{O}$ delineamento estatístico foi o inteiramente casualizado. A avaliação dos sintomas foi realizada aos 20 dias após a inoculação, com base em escala diagramática (Piccinin, 1995). Algumas plantas de sorgo foram tratadas com as preparações das cianobactérias e posteriormente aspergidas com água para verificação de sintomas de fitotoxicidade. Todos os experimentos foram conduzidos por duas vezes.

\section{RESULTADOS}

Determinação dos conteúdos de açúcares redutores e proteínas totais nos filtrados das cianobactérias

A concentração de açúcares redutores e proteínas totais nos filtrados das cianobactérias aumentou com a idade de 
cultivo das mesmas (Tabela 1). Esse aumento foi significativo já aos 70 dias de cultivo para os filtrados de $S$. leopoliensis, mas não para os de Nostoc sp., onde a elevação somente ocorreu em filtrados de culturas mais velhos (no caso, 140 dias de cultivo). Provavelmente, a capacidade fotossintética de tais microrganismos e o cultivo sob condições apropriadas para expressão de tal atividade propiciaram os aumentos considerados. A diferença encontrada entre as cianobactérias poderia se relacionar com a velocidade de crescimento das mesmas, visto que $S$. leopoliensis apresenta uma taxa de multiplicação celular bem superior à de Nostoc sp. (Di Piero et al., 2000).

Efeito das cianobactérias sobre a germinação de esporos e a formação de apressórios por $\boldsymbol{C}$. sublineolum

Os meios líquidos de cultivo (BG11 e AA/4) foram inibitórios à germinação dos conídios de C. sublineolum (Figura 1). Ao contrário, os filtrados obtidos a partir de culturas de S. leopoliensis e Nostoc sp., com 70 e 140 dias de cultivo, estimularam a germinação de conídios de $C$. sublineolum (Figura 1A). Considerando a influência de $S$. leopoliensis sobre a formação de apressórios pelo fitopatógeno (Figura 1B), não houve diferenças significativas das preparações comparadas aos controles (água e BG 11). Porém, as preparações de Nostoc sp. inibiram a formação de apressórios quando comparadas com o tratamento água, mas não quando comparadas com o tratamento envolvendo o meio líquido AA/4.

Efeito das cianobactérias sobre o crescimento de $C$. sublineolum em meio de cultivo

Os filtrados incorporados em BDA a $20 \%$ não apresentaram efeito no crescimento do fungo, independente da idade de cultivo das cianobactérias quando da obtenção dos mesmos (dados não apresentados). Porém, quando utilizados a $40 \%$, os filtrados de $S$. leopoliensis com diferentes idades estimularam o crescimento do patógeno em comparação com o meio BDA normal, enquanto os filtrados de Nostoc sp. não afetaram o crescimento micelial do fungo (Figura 2).

TABELA 1 - Concentração de açúcares redutores e proteínas totais nos filtrados de Nostoc sp. (N) e Synechococcus leopoliensis (S), obtidos a partir de culturas com diferentes idades de crescimento

\begin{tabular}{lcc}
\hline \hline Filtrado & $\begin{array}{c}\text { Açúcares redutores } \\
(\boldsymbol{\mu g} / \mathbf{m l})\end{array}$ & $\begin{array}{c}\text { Proteínas totais }^{2} \\
(\boldsymbol{\mu g} / \mathbf{m l})\end{array}$ \\
\hline $\mathrm{N}-30$ dias & $7,9 \pm 2,7 \mathrm{a}^{3}$ & $15,4 \pm 5,1 \mathrm{a}^{3}$ \\
$\mathrm{~N}-70$ dias & $11,1 \pm 1,0 \mathrm{a}$ & $43,9 \pm 30,5 \mathrm{a}$ \\
$\mathrm{N}-140$ dias & $34,2 \pm 3,5 \mathrm{abc}$ & $153,5 \pm 13,4 \mathrm{~b}$ \\
\hline $\mathrm{S}-30$ dias & $17,1+6,4 \mathrm{a}$ & $38,4+8,3 \mathrm{a}$ \\
$\mathrm{S}-70$ dias & $31,7 \pm 9,4 \mathrm{~b}$ & $111,8 \pm 27,5 \mathrm{~b}$ \\
$\mathrm{~S}-140$ dias & $55,0 \pm 5,5$ d & $162,1 \pm 14,9 \mathrm{~b}$ \\
\hline
\end{tabular}

${ }^{1}$ Determinação pelo método de Lever (1972).

${ }^{2}$ Determinação pelo método de Bradford (1976).

${ }^{3}$ Valores representam a média \pm desvio padrão. Médias seguidas pela mesma letra, na coluna, não diferem entre si pelo teste de Tukey a $5 \%$.
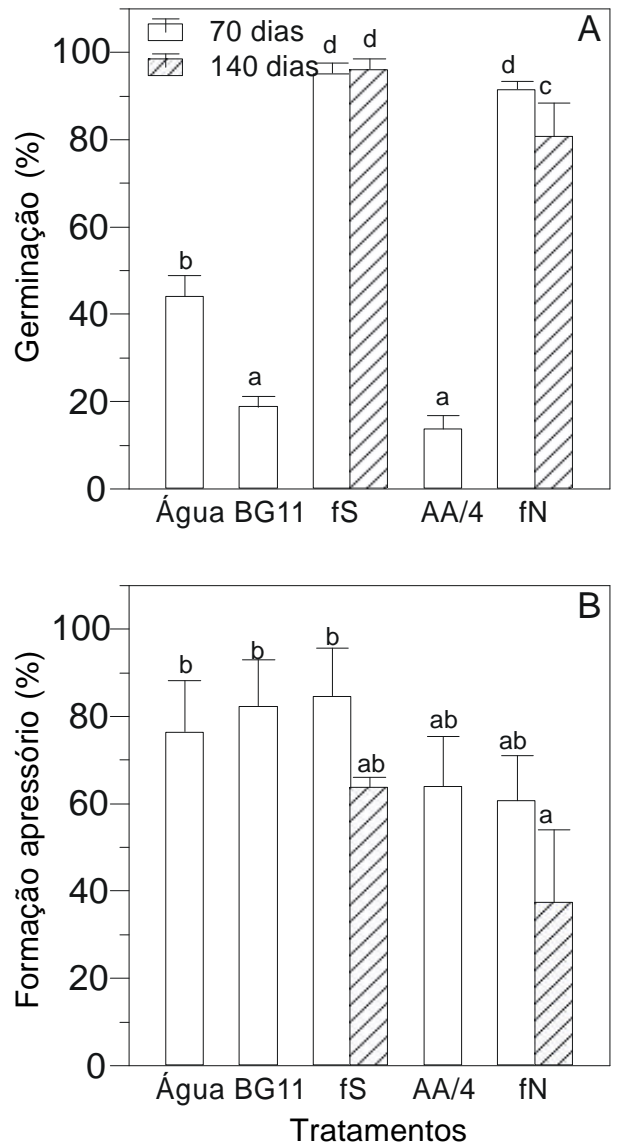

FIG. 1 - Influência dos filtrados obtidos a partir das cianobactérias, com 70 e 140 dias de cultivo, na germinação (A) e na formação de apressório (B) por Colletotrichum sublineolum. BG 11 e AA/4 $=$ meios de cultivo; $\mathbf{f}=$ filtrado; $\mathrm{S}=$ Synechococcus leopoliensis; $\mathrm{N}=$ Nostoc sp. As barras representam a média \pm o desvio padrão. Médias seguidas pela mesma letra não diferem entre si pelo teste de Tukey a $5 \%$.

Efeito das cianobactérias no acúmulo de fitoalexinas em mesocótilos de sorgo

Preparações obtidas a partir de $S$. leopoliensis (suspensão de células e filtrados) em diferentes tempos de cultivo (30, 70 e 140 dias) não diferiram estatisticamente dos controles representados pelo meio de cultivo da cianobactéria (BG 11) e pela água (Figura 3). No caso de Nostoc sp., os preparados que induziram maior acúmulo de fitoalexinas em sorgo apresentaram um desvio padrão muito grande, fazendo com que não diferissem estatisticamente dos controles água e $\mathrm{AA} / 4$.

Efeito protetor das cianobactérias na interação sorgo x $C$. sublineolum

Plantas de sorgo tratadas com o meio líquido BG 11 (meio de cultivo para $S$. leopoliensis) foram as que apresentaram maior severidade média de doença (Figura 4). 
Efeito das cianobactérias Synechococcus leopoliensis e Nostoc sp. sobre Colletotrichum...

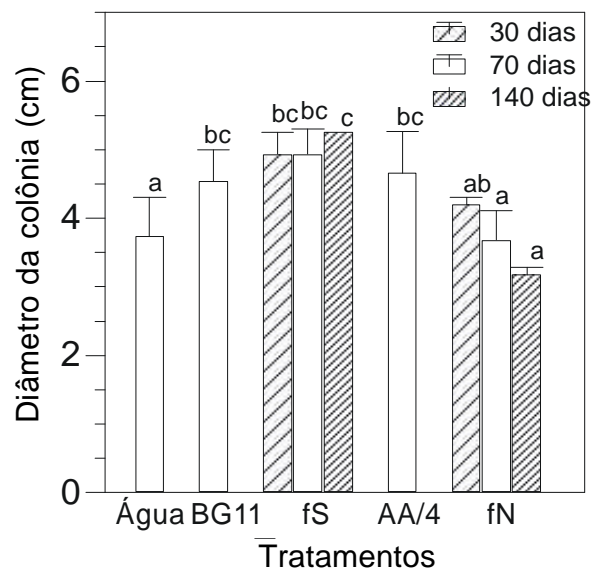

FIG. 2 - Influência dos filtrados obtidos a partir das cianobactérias com 30, 70 e 140 dias de cultivo, e utilizados a $40 \%$, no crescimento vegetativo de Colletotrichum sublineolum em meio de BDA. Resultados obtidos 7 dias após a repicagem do fungo. BG 11 e AA/4 = meios de cultivo; $f=$ filtrado; $\mathbf{S}=$ Synechococcus leopoliensis; $\mathbf{N}=$ Nostoc $\mathbf{s p}$. Barras representam a média \pm desvio padrão. Médias seguidas pela mesma letra não diferem entre si pelo teste de Tukey a 5\%.

Em muitas folhas nesse tratamento foram notadas lesões típicas de fitotoxidez, caracterizadas pelo formato arredondado e cor esbranquiçada, o que pode ter contribuído para o resultado obtido. No tocante às preparações de S. leopoliensis, as mesmas não diferiram estatisticamente dos controles representados pela água e por BG 11 .

Por sua vez, as plantas tratadas com preparações de Nostoc sp. mostraram menor severidade de doença quando comparadas às tratadas com S. leopoliensis, mas sem diferença estatística entre esses tratamentos. Também não se pode confirmar um efeito protetor por parte de Nostoc sp., visto as plantas tratadas com essa cianobactéria não apresentarem severidade de doença significativamente menor que as tratadas com água (Figura 4).

No teste conduzido sob esquema booster, todos os tratamentos diferiram estatisticamente do controle representado pela água, com uma pequena redução na severidade da antracnose em sorgo (Figura 5).

\section{DISCUSSÃO}

As cianobactérias S. leopoliensis e Nostoc sp. não apresentaram efeito antagônico in vitro a $C$. sublineolum, agente causal da antracnose do sorgo. Pelo contrário, ocorreu um estímulo à germinação de conídios e ao crescimento micelial do patógeno, após o tratamento com os filtrados de culturas obtidos a partir das cianobactérias. Esses filtrados poderiam conter substâncias estimulatórias produzidas pelas cianobactérias ou simplesmente apresentarem nutrientes em concentrações favoráveis ao fitopatógeno. Sabe-se que a

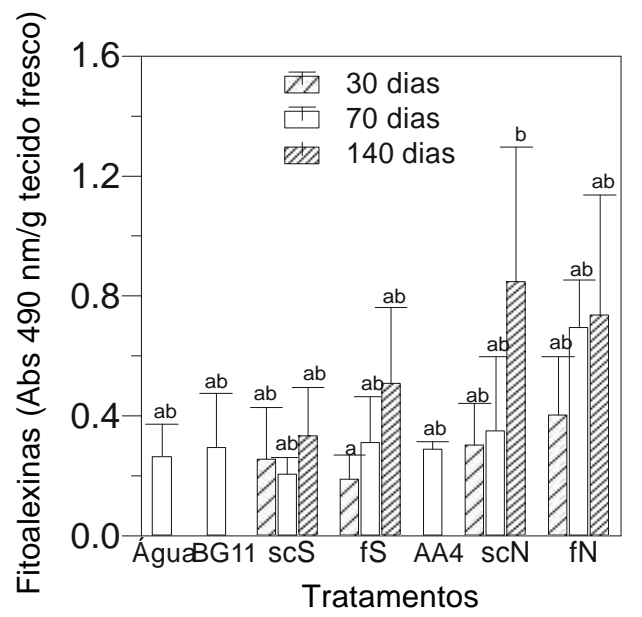

Fig. 3 - Atividade elicitora do acúmulo de fitoalexinas em mesocótilos de sorgo (Sorghum bicolor) por preparações das cianobactérias com 30, 70 e 140 dias de cultivo. BG 11 e AA/4 = meios de cultivo; $\mathbf{s c}=$ suspensão de células; $\mathbf{f}=$ filtrado; $\mathrm{S}=$ Synechococcus leopoliensis; $\mathrm{N}=$ Nostoc $\mathbf{s p}$. As barras representam a média \pm o desvio padrão. Médias seguidas pela mesma letra não diferem entre si pelo teste de Tukey a $5 \%$. O controle positivo (suspensão de esporos de $C$. sublineolum - 1x10 conídios $/ \mathrm{ml}$ ) exibiu Abs $490 \mathrm{~nm} / \mathrm{g}$ tecido fresco $=28,1 \pm 2,3$.

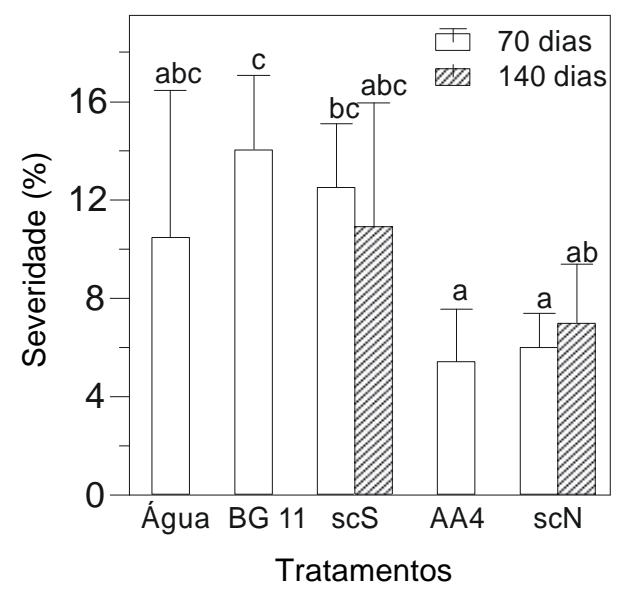

Fig. 4 - Efeito das suspensões de células de cianobactérias, obtidas a partir de culturas com 70 e 140 dias de cultivo, na severidade da antracnose em sorgo (Sorghum bicolor). Os tratamentos foram realizados 2 dias antes da inoculação das plantas com Colletotrichum sublineolum. BG 11 e AA/4 = meios de cultivo; $\mathbf{s c}=$ suspensão de células; $\mathrm{S}=$ Synechococcus leopoliensis; $\mathbf{N}=$ Nostoc $\mathbf{s p}$. As barras representam a média \pm o desvio padrão. Médias seguidas pela mesma letra não diferem entre si pelo teste de Duncan a $10 \%$. 


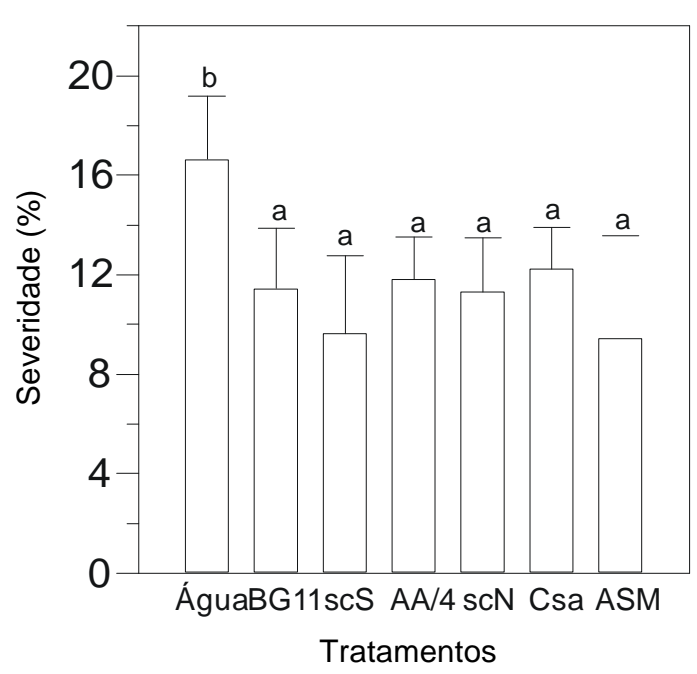

FIG. 5 - Efeito de diferentes preparações e de um ativador de defesa vegetal na severidade da antracnose em sorgo (Sorghum bicolor). Os tratamentos foram aplicados duas vezes, com um intervalo de um dia, e a inoculação das plantas com Colletotrichum sublineolum foi realizada 2 dias após a segunda aplicação dos tratamentos. BG 11 e AA/4 = meios de cultivo das cianobactérias; $\mathbf{s c}=$ suspensão de células; $\mathbf{S}=$ Synechococcus leopoliensis; $\mathbf{N}=$ Nostoc sp.; Csa $=$ suspensão de esporos de $C$. sublineolum autoclavada $\left(1 \times 10^{5}\right.$ conídios $\left./ \mathrm{ml}\right)$; ASM = acibenzolar S-metil (ativador de defesa vegetal), utilizado a 50 ppm i.a. As suspensões de células de cianobactérias foram obtidas a partir de culturas com 70 dias de cultivo. As barras representam a média \pm o desvio padrão. Médias seguidas pela mesma letra não diferem entre si pelo teste de Duncan a $\mathbf{1 0 \%}$.

presença de nutrientes prontamente disponíveis, em concentrações adequadas, inativa a micosporina-alanina, um autoinibidor de germinação encontrado na mucilagem que envolve os conídios de C. sublineloum (Leite \& Nicholson, 1993). Por outro lado, a inibição na germinação verificada com os meios líquidos BG 11 e AA/4 provavelmente ocorreu em virtude da quantidade excessiva de alguns dos nutrientes contidos nesses meios.

Quanto ao desenvolvimento micelial in vitro do fitopatógeno, o fato da incorporação do meio líquido BG 11 (meio de cultivo de $S$. leopoliensis, rico em sais minerais) a $40 \%$ em BDA, ter propiciado um estímulo ao crescimento micelial de C. sublineolum tanto quanto os filtrados obtidos a partir de S. leopoliensis, indica que a quantidade e/ou qualidade de nutrientes presentes nesses tratamentos foi a principal causa do resultado observado. $\mathrm{O}$ fungo também teve seu crescimento micelial aumentado no tratamento com o meio líquido onde Nostoc sp. é cultivada (AA/4), utilizado a 40\%. No entanto, o crescimento do fungo nos tratamentos com filtrados obtidos a partir de Nostoc sp. não diferiu do encontrado em BDA normal, o que significa que esta cianobactéria pode estar indisponibilizando os nutrientes contidos no meio AA/4, resultando em ausência de estímulo ao crescimento de $C$. sublineolum.

Os filtrados obtidos a partir de Nostoc sp. com até 70 dias de cultivo apresentaram de modo geral, teores menores de açúcares e proteínas em relação aos de S. leopoliensis (Tabela 1). Os obtidos de culturas de Nostoc sp. com 140 dias, no entanto, mostraram-se com valores relativamente altos e mesmo assim, não estimularam o crescimento micelial de C. sublineolum. Como as dosagens de açúcares redutores e proteínas totais foram quantitativas e não qualitativas, não foi possível o estabelecimento de relações mais apuradas.

Mesmo sem apresentar efeito antagônico direto contra o fitopatógeno, as cianobactérias poderiam proteger plantas de sorgo, caso conseguissem atuar como indutoras de resistência. $\mathrm{O}$ bioensaio com mesocótilos de sorgo para a quantificação de fitoalexinas contribui no sentido de serem encontrados compostos com potencial de ativar os mecanismos de defesa dessa planta (Lopes, 1993) e por isso foi utilizado no presente trabalho. Fitoalexinas em sorgo são sintetizadas em inclusões dentro das células sob ataque de patógenos, movem-se para o sítio de penetração e liberam seus conteúdos junto ao citoplasma, e a síntese adicional de fitoalexinas ocorre nas células vizinhas (Snyder \& Nicholson, 1990).

O sorgo é uma das poucas plantas monocotiledôneas que sintetizam fitoalexinas em resposta à infecção por patógenos. Plantas juvenis de cultivares geneticamente resistentes e suscetíveis sintetizam fitoalexinas e resistem ao fungo, mas as cultivares suscetíveis maduras perdem a habilidade de responder rapidamente à infecção fúngica (Tenkouano et al., 1993). Uma hipótese é que as cultivares suscetíveis produzem fitoalexinas em todos os estádios, mas os compostos somente se acumulem em níveis fungitóxicos em plantas juvenis.

A ausência de proteção encontrada em plantas suscetíveis de sorgo tratadas com as cianobactérias pode ser reflexo da baixa capacidade de induzirem o acúmulo de fitoalexinas em mesocótilos de sorgo. Os metabólitos e células das cianobactérias testadas parecem não estimular os tecidos de sorgo, de forma a não ativar os mecanismos latentes de resistência da planta, e conseqüentemente não propiciar proteção contra $C$. sublineolum. A aplicação das cianobactérias sobre sorgo em esquema booster (aplicações de um mesmo indutor com um intervalo de tempo entre elas), no último experimento realizado, pode ter modificado esse panorama.

Em muitos casos, uma única aplicação do indutor é suficiente para induzir resistência a doenças, como verificado pelo uso de ASM (30 g i.a./ha) em trigo de inverno, no estádio GS 25-32, que protegeu a cultura ao longo da estação de crescimento contra Blumeria graminis Speer f. sp. tritici, agente causal do oídio (Stadnik \& Buchenauer, 1999). Por outro lado, aplicações em esquema booster têm mostrado aumentar o período de proteção de arroz tratado com ácido salicílico contra Magnoporthe grisea (Hebert) Barr (Cai \& 
Zheng, 1996), bem como melhorar a eficiência de metabólitos produzidos por Bacillus subtilis (Cohn) Prazmowski em controlar oídio do trigo (Schönbeck et al., 1982). No caso de arroz tratado com o não-patógeno Bipolaris sorokiniana Sacc. atuando como um indutor biótico, somente múltiplas aplicações, realizadas em diferentes estádios da cultura, foram eficazes em proteger as plantas contra Pyricularia oryzae Cavara, em experimento de campo conduzido no Nepal (Manandhan et al., 1998).

Mesmo considerando-se o resultado da aplicação em booster, as cianobactérias S. leopolienis e Nostoc sp. pouco afetaram a antracnose em sorgo nas condições estudadas, não revelando, até o momento, potencial para atuarem como agentes controladores dessa importante doença do sorgo.

\section{REFERÊNCIAS BIBLIOGRÁFICAS}

AGUIAR, R.M. Estudo de fatores que interferem no crescimento de cianobactérias de vida livre, fixadoras de nitrogênio, e o isolamento de mutantes espontâneos. (Dissertação de Mestrado). Piracicaba. Escola Superior de Agricultura "Luiz de Queiroz"/USP. 1992.

ALLEN, M.M. Simple conditions for growth of unicellular bluegreen algae on plates. Journal of Phycology 4:1-4. 1968.

ALLEN, M.B. \& ARNON, D.I. Studies on nitrogen-fixing bluegreen algae. I. Growth and nitrogen fixation by Anabaena cylindrica Lemm. Plant Physiology 30:366-372. 1955.

BRADFORD, M.A. A rapid and sensitive method for the quantitation of microgram quantities of protein utilizing the principle of protein-dye binding. Analytical Biochemistry 72248-254. 1976.

CAI, X.Z. \& ZHENG, Z. Effect of exogenous salicylic acid on resistance of rice seedlings to blast. Chinese Rice Research Newsletter 4:8-9. 1996.

CANNELL, R.J.P. Algae as a source of biologically active products. Pesticide Science 39:147-153. 1993.

CASELA, C.R. \& FREDERIKSEN, R.A. Evidence for dilatory resistance to anthracnose in sorghum. Plant Disease 77:908-911. 1993.

DE CAIRE, G.Z., MULÉ, M.C.Z. de, HALPERIN, D.R. de \& GALVAGNO, M. Action of cell-free extracts and extracellular products of Nostoc muscorum on growth of Sclerotinia sclerotiorum. Phyton 47:43-46. 1987.

DE MEYER, G., BIGIRIMANA, J., ELAD, Y. \& HOFTE, M. Induced systemic resistance in Trichoderma harzianum T39 biocontrol of Botrytis cinerea. European Journal of Plant Pathology 104:279-286. 1998.

DI PIERO, R.M., PASCHOLATI, S.F \& REZENDE, J.A.M. Efeito das cianobactérias Synechococcus leopoliensis e Nostoc sp. na infectividade do vírus do mosaico do fumo (TMV). Summa Phytopathologica 26:215-220. 2000.

KUC, J. Plant immunization and its applicability for disease control. In: Chet, I. (Ed.) Innovative Approaches to Plant Disease Control. New York. John Wiley \& Sons. 1987. pp.255-274.
KULIK, M.M. The potential for using cyanobacteria (blue-green algae) and algae in the biological control of plant pathogenic bacteria and fungi. European Journal of Plant Pathology 101:585-599. 1995.

LEITE, B. \& NICHOLSON, R.L. Mycosporine-alanine: a self-inhibitor of germination from the conidial mucilage of Colletotrichum graminicola. Experimental Mycology 16:7686. 1992.

LEITE, B. \& NICHOLSON, R.L. A volatile self-inhibitor from Colletotrichum graminicola. Mycologia 86:945-951. 1993.

LEVER, M. A new reaction for colorimetric determination of carbohydrates. Analytical Biochemistry 47:273-279. 1972.

LOPES, A.M.Q. Fitoalexinas em sorgo - papel na interação com fungos fitopatogênicos. Summa Phytopathologica 19:59-61. 1993.

MANANDHAR, H.K., JORGENSEN, H.J.L., MATHUR, S.B. \& SMEDEGAARD-PETERSEN, V. Suppression of rice blast by preinoculation with avirulent Pyricularia oryzae and the nonrice pathogen Bipolaris sorokiniana. Phytopathology 88:735-739. 1998.

NICHOLSON, R.L., KOLLIPARA, S.S., VICENT, J.R., LYONS, P.C. \& CADENA-GOMEZ, G. Phytoalexin synthesis by the sorghum mesocotyl in response to infection by pathogenic and nonpathogenic fungi. Proceedings of the National Academy of Science of the U.S.A. 84:5520-5524. 1987.

PICCININ, E. Uso de Saccharomyces cerevisiae na proteção de plantas de sorgo (Sorghum bicolor), maracujá azedo amarelo (Passiflora edulis) e eucalipto (Eucalyptus spp.) contra fitopatógenos fúngicos e bacterianos. (Dissertação de Mestrado). Piracicaba. Escola Superior de Agricultura "Luiz de Queiroz"/USP. 1995.

ROVERATTI, D.S. Proteção de plantas de café (Coffea arabica L.) contra Hemileia vastatrix Berk. et Br. por Saccharomyces cerevisiae. (Dissertação de Mestrado). Piracicaba. Escola Superior de Agricultura “Luiz de Queiroz”/USP. 1989.

SCHÖNBECK, F., DEHNE, H. \& BALDER, H. The efficiency of induced resistance under practical culture conditions. Zeitschrift fur Pflanzenkrankheiten und Pflanzenschutz 89:177184. 1982.

SNYDER, B.A \& NICHOLSON, R.L. Synthesis of phytoalexins in sorghum as a site-specif response to fungal ingress. Science 248:1637-1639. 1990.

STADNIK, M.J. \& BUCHENAUER, H. Control of wheat diseases by a benzothiadiazole-derivate and modern fungicides. Zeitschrift fur Pflanzenkrankheiten und Pflanzenschutz 106:476-489. 1999.

TENKOUANO, A., MILLER, F.R., HART, G.E., FREDERIKSEN, R.A. \& NICHOLSON, R.L. Phytoalexin assay in juvenile sorghum: an aid to breeding for anthracnose resistance. Crop Science 33:243-248. 1993.

VIDHYASEKARAN, P., RABINDRAN, R., MUTHAMILAN, M., NAYAR, K., RAJAPPAN, K., SUBRAMANIAN, N. \& VASUMATHI, K. Development of a powder formulation of Pseudomonas fluorescens for control of rice blast. Plant Pathology 46:291-297. 1997. 